\title{
Connexin-43 upregulation in micrometastases and tumor vasculature and its role in tumor cell attachment to pulmonary endothelium
}

\author{
M Khair Elzarrad ${ }^{1}$, Abu Haroon ${ }^{1}$, Klaus Willecke ${ }^{2}$, Radoslaw Dobrowolski², \\ Mark N Gillespie ${ }^{1}$ and Abu-Bakr Al-Mehdi*1
}

Address: ${ }^{1}$ Department of Pharmacology and Center for Lung Biology, University of South Alabama, North University Boulevard, Mobile, AL 36688, USA and 2University of Bonn, Institute for Genetics, Roemerstrasse, 53117 Bonn, Germany

Email: M Khair Elzarrad - mke303@jaguar1.usouthal.edu; Abu Haroon - atmyharoon@yahoo.com; Klaus Willecke - genetik@uni-bonn.de; Radoslaw Dobrowolski - DobrowolskiR@uni-bonn.de; Mark N Gillespie - mgillesp@jaguar1.usouthal.edu; Abu-Bakr AlMehdi* - aalmehdi@jaguar1.usouthal.edu

* Corresponding author

Published: 22 July 2008

BMC Medicine 2008, 6:20 doi:10.1186/1741-7015-6-20
Received: 13 June 2008

Accepted: 22 July 2008

This article is available from: http://www.biomedcentral.com/I74I-70I5/6/20

(c) 2008 Elzarrad et al; licensee BioMed Central Ltd.

This is an Open Access article distributed under the terms of the Creative Commons Attribution License (http://creativecommons.org/licenses/by/2.0), which permits unrestricted use, distribution, and reproduction in any medium, provided the original work is properly cited.

\begin{abstract}
Background: The modulation of gap junctional communication between tumor cells and between tumor and vascular endothelial cells during tumorigenesis and metastasis is complex. The notion of a role for loss of gap junctional intercellular communication in tumorigenesis and metastasis has been controversial. While some of the stages of tumorigenesis and metastasis, such as uncontrolled cell division and cellular detachment, would necessitate the loss of intercellular junctions, other stages, such as intravasation, endothelial attachment, and vascularization, likely require increased cell-cell contact. We hypothesized that, in this multi-stage scheme, connexin- 43 is centrally involved as a cell adhesion molecule mediating metastatic tumor attachment to the pulmonary endothelium.

Methods: Tumor cell attachment to pulmonary vasculature, tumor growth, and connexin- 43 expression was studied in metastatic lung tumor sections obtained after tail-vein injection into nude mice of syngeneic breast cancer cell lines, overexpressing wild type connexin- 43 or dominant-negatively mutated connexin43 proteins. High-resolution immunofluorescence microscopy and Western blot analysis was performed using a connexin- 43 monoclonal antibody. Calcein Orange Red AM dye transfer by fluorescence imaging was used to evaluate the gap junction function.

Results: Adhesion of breast cancer cells to the pulmonary endothelium increased with cancer cells overexpressing connexin- 43 and markedly decreased with cells expressing dominant-negative connexin43. Upregulation of connexin- 43 was observed in tumor cell-endothelial cell contact areas in vitro and in vivo, and in areas of intratumor blood vessels and in micrometastatic foci.

Conclusion: Connexin- 43 facilitates metastatic 'homing' by increasing adhesion of cancer cells to the lung endothelial cells. The marked upregulation of connexin-43 in tumor cell-endothelial cell contact areas, whether in preexisting 'homing' vessels or in newly formed tumor vessels, suggests that connexin- 43 can serve as a potential marker of micrometastases and tumor vasculature and that it may play a role in the early incorporation of endothelial cells into small tumors as seeds for vasculogenesis.
\end{abstract}




\section{Background}

Intercellular communication via gap junctions between neighboring cells contributes to the organization of cells into functional tissues. Malignant tumors arising from planar epithelial tissue lose the normal growth limit caused by cell-cell contacts and form solid tumors in three dimensions. This observation was the origin of the notion that the loss of gap junctional intercellular communication (GJIC) plays an important role in tumorigenesis $[1,2]$. Moreover, since invasive tumors are characterized by cell detachment from the primary mass, a disruption of intercellular junctions also became a de facto requirement for metastasis $[3,4]$.

A tumor cell undergoes a variety of stages in its life cycle: its origin and growth in the primary site, cellular detachment and intravasation, dissemination, settling in a new site by endothelial attachment, and its growth as a metastatic tumor including the development of its blood supply. While some of these stages, such as uncontrolled cell division and cellular detachment, are associated with loss of intercellular junctions, other stages, such as intravasation, endothelial attachment, and vascularization, demand increased cell-cell contact. Therefore, it is clear that a simplistic notion of the loss of cellular communication cannot fully describe the status of the cellular interaction between tumor cells or between endothelial and tumor cells during the whole metastatic process. An adhesive interaction of tumor cells to endothelial cells during 'homing' is obvious. In addition, a role for connexins in the facilitation of tumor growth, metastatic potential, and tumor vascularization has been documented [5-12].

We have demonstrated that endothelial cells are incorporated early in breast cancer metastatic tumors in the lung before the onset of hypoxia and they grow in mixed fashion among the tumor cells, contributing to tumor vascularization. These disparate cell types were shown to establish functional GJIC both in vivo and in vitro. Since the role of gap junctions in tumorigenesis and metastasis has been controversial as outlined above, we addressed the following questions in this work.

1. Does connexin-43 (Cx43) mediate GJIC between 4T1GFP cells and pulmonary microvascular endothelial cells (PMVECs)?

2. Does Cx43 play a role in the attachment of breast cancer cells to endothelial cells in the pulmonary circulation?

3. Is $\mathrm{Cx} 43$ upregulation associated with the sites of micrometastatic foci and metastatic tumor vasculature?

To understand the role of $\mathrm{Cx} 43$ in the metastatic process, we used cancer cell lines that overexpress wild-type Cx43, express a dominant-negative mutant of $\mathrm{Cx} 43$, and a control mutant that does not affect endogenous Cx43 functions. Using these Cx43 mutant cell lines, we show that in a syngeneic mouse breast cancer experimental metastasis model, Cx43 enhances breast cancer cell attachment to the pulmonary endothelium. The results also indicate that Cx43 can serve as a marker of micrometastases and tumor vasculogenesis because of its significant upregulation in areas of tumor cell-endothelial cell contact areas in vitro and in vivo.

\section{Methods}

\section{Cell culture and stable expression of Cx43 mutants}

Pulmonary microvascular endothelial cells were obtained from the Endothelial Cell Culture Core at the Center for Lung Biology [13]. These cells are routinely obtained by primary isolation from Sprague-Dawley rats and are used within passage 12 . These cells are maintained and propagated in Dulbecco's Modified Eagle's Medium (DMEM) with $10 \%$ fetal bovine serum.

The 4T1 cells (a mouse breast adenocarcinoma cell line) were obtained from ATCC and were transfected with enhanced green fluorescent protein (eGFP) vector (Clontech, Mountain View, CA). Cells with stable GFP expression were separated by fluorescence activated cell sorting and propagated and maintained in DMEM with 10\% fetal bovine serum. We have used the 4T1-GFP cells previously in both experimental and spontaneous metastasis assays [14-16]. Cells were grown in DMEM supplemented with $10 \%$ fetal bovine serum, 100 units $/ \mathrm{ml}$ penicillin and 100 $\mathrm{mg} / \mathrm{ml}$ streptomycin and were maintained at $37^{\circ} \mathrm{C}$ in a moist environment of $95 \%$ air and $5 \% \mathrm{CO}_{2}$ and sub-cultured as required.

The Cx43 missense mutation G138R was made by sitedirected mutagenesis by changing the glycine to arginine on position 138 in the amino acid sequence. The G138R mutant expresses a mutant $\mathrm{Cx} 43$ that exhibits a dominant-negative effect when expressed in cells with endogenous Cx43 [17]. This mutation is known to be present in patients suffering from oculodentodigital dysplasia $[18,19]$. The expressed Cx43-G138R protein translocates to the membrane, and assembles as connexons, but does not exhibit functional GJIC. Cells expressing the G138R mutation exhibited a strong suppression of dye-transfer even when they were co-expressed with wild-type Cx43 [17]. The G138R construct was ligated to a eukaryotic expression vector containing the zeocin resistance gene driven by the SV40 promoter. On the other hand, the C61S mutant Cx43 protein lacks gap junction channel forming abilities because of its cytoplasmic localization, and apparently it does not interfere with functional gap junction formation by endogenous normal Cx43 [20]. The Cx43 point mutation C61S was generated by site- 
directed mutagenesis, replacing the cysteine residue in position 61 with a serine residue. The C61S construct was primarily used as a control. Both the C61S construct and the cDNA for wild-type $\mathrm{Cx} 43$ (Cx43 overexpressors, or $\mathrm{Cx} 43 \mathrm{OE})$ were ligated into the expression vector pBEHpac18. 4T1-GFP tumor cells were also transfected with the vector expressing two copies of wild-type Cx43 (Cx43OE) to enhance the formation of functional gap junctions in tumor cells (positive control).

Plasmid DNA was extracted from filter paper spots into $500 \mu \mathrm{l}$ of Tris-EDTA buffer $(10 \mathrm{mM}$ Tris-Cl, pH 7.5 and 1 mM EDTA), electroporated into competent bacteria, and allowed to grow overnight with the appropriate antibiotic for selection. The plasmid DNA was isolated using Miniprep (Qiagen) and samples were run on a gel to confirm the size of the plasmid. In addition, samples of the plasmid DNA were sent to the GeneLab at Louisiana State University (Baton Rouge, LA) for amplification and sequencing. The presence of each mutation was confirmed by comparison with wild type using BLAST software.

4T1-GFP cells were grown to 75-95\% confluency in 60 $\mathrm{mm}$ culture dishes and transfected at $37^{\circ} \mathrm{C}$ in Opti-MEM medium (Invitrogen, Carlsbad, CA) containing $75 \mu \mathrm{l}$ of Lipofectamine 2000 and $30 \mu \mathrm{g}$ of plasmid DNA. After 24 hours, the DNA/Lipofectamine suspension was removed and replaced with culture medium containing the appropriate antibiotics. Cells were selected with $2 \mu \mathrm{g} / \mathrm{ml}$ puromycin (InvivoGen, San Diego, CA) for the C61S and Cx43OE constructs or with $500 \mu \mathrm{g} / \mathrm{ml}$ of zeocin (Invitrogen) for the G138R construct. The selection process continued for 2 weeks on the puromycin resistance constructs and for 4 weeks on the zeocin resistant construct. Cells were maintained afterwards in normal medium containing the appropriate amounts of antibiotics.

\section{Evaluation of gap junctions by dye-transfer assays in vitro and in situ}

The presence of functional gap junctions was evaluated using a fluorescent dye-transfer assay. Sub-confluent monolayers of PMVECs in glass-bottomed $35 \mathrm{~mm}$ dishes were used. Endothelial cells were washed with Kreb's Ringer bicarbonate solution (KRB), with 5\% clinical grade dextran and $10 \mathrm{mM}$ glucose at $\mathrm{pH}$ 7.4, and incubated with $5 \mu \mathrm{M}$ Calcein Orange Red AM (gap junction-permeable fluorescent dye, molecular weight $790 \mathrm{Da}$ ) in KRB for 30 minutes. The acetoxymethyl ester (AM) group of the dye is hydrolyzed by esterases in a viable cell, rendering the dye polarized and trapped within the cell, but allowing its transfer to adjacent cells via functional gap junctions. After dye loading, the endothelial cells were washed five times to remove the free dye from the medium. Experiments were performed in KRB in the absence of serum.
Then 4T1-GFP cells (transferred-dye acceptors) were placed on the labeled endothelial cells (dye donors) at a ratio of 1:500 (acceptor:donor). After incubating for up to 3 hours at $37^{\circ} \mathrm{C}$, the cells were washed and visualized using a Nikon TE2000 epifluorescence microscope. For in situ dye-transfer studies, $5 \mu \mathrm{M}$ Cell Tracker Orange was used to label pulmonary endothelial cells in situ and then Calcein Green AM labeled 4T1 cancer cells (without GFP) were administered in the perfusate of mouse lungs and dye transfer to endothelial cells in situ was evaluated by confocal microscopy (BioRad Radiance 2000, Hercules, $\mathrm{CA}$ ). All fluorescent probes were obtained from Invitrogen Molecular Probes (Eugene, OR).

\section{Immunocytofluorescence for Cx43}

Following stable transfection with wild-type or mutant DNA constructs, cells were grown on glass-bottomed 35 $\mathrm{mm}$ dishes and were fixed in ice-cold $70 \%$ methanol and $20 \%$ acetone solution for 10 minutes at $4^{\circ} \mathrm{C}$, then rinsed with phosphate buffered saline (PBS) and prepared for immunolabeling. Non-specific antigen sites were blocked with $2 \%$ bovine serum albumin (BSA) in PBS, immunolabeled with the Cx43 primary antibody, washed with PBS and labeled with a fluorescent secondary antibody. Cells were then washed in PBS, air-dried, and cover-slipped with a drop of the mounting medium Gold Antifade Reagent containing 4',6-diamidino-2-phenylindole (DAPI) for nuclear staining (Invitrogen, Carlsbad, CA).

\section{Western blot analysis and densitometry}

Lysates of 4T1-GFP cells collected from stable colonies after transfection with $30 \mu \mathrm{g}$ of wild-type or mutant cDNA encoding C61S or G138R were subjected to Western blotting. Blots were immunolabeled for $\mathrm{Cx} 43$ using a mouse anti-Cx43 monoclonal antibody (catalog \#13-8300, Zymed, San Francisco, CA). Unsaturated blots were scanned and densitometry was performed using Quantity One software (BioRad, Hercules, CA).

\section{Immunohistochemistry/immunohistofluorescence}

Immunohistochemistry was carried out on paraffinembedded mouse lung tissue sections containing tumor segments. Sections were deparaffinized in two changes of xylene then hydrated in sequential changes of decreasing concentrations of ethanol (100\%, 90\%, 70\%, 50\%, 30\%) followed by a rinse in distilled water. Antigen retrieval was performed by immersing the slides in sodium citrate buffer (10 mM sodium citrate, $0.05 \%$ Tween 20 , pH 6.0) at boiling temperature. Slides were then cooled at room temperature for 20 minutes and rinsed in PBS buffer containing $0.1 \%$ Triton X-100. Nonspecific binding was blocked using 5\% goat serum and 5\% BSA and $0.3 \%$ Triton X-100 for 30 minutes. Slides were incubated with mouse anti-Cx43 monoclonal antibody (\#35-5000, Zymed, San Francisco, CA) for 2 hours at room tempera- 
ture. Slides were rinsed again and incubated for 1 hour with a secondary antibody conjugated to a fluorescent probe (Alexa Fluor 647) or horseradish peroxidase (HRP). Slides were then washed in PBS, air-dried, and coverslipped with a drop of the mounting medium Gold Antifade Reagent containing DAPI for nuclear staining (Invitrogen, Carlsbad, CA).

\section{Quantification of tumor cells adhering to the lung vasculature}

Immunohistofluorescence and immunohistochemistry slides were imaged using the Nikon TE2000 epifluorescence microscope with a $\times 60$ objective. Three lungs from animals containing tumors derived from each cell line were used. Four slides from each lung were used for imaging. Twenty contiguous picture frames per slide were acquired. Cells were counted in each stitched meta-picture.

\section{Fluorescence microscopy}

A high-resolution digital fluorescence video imaging system based on a Nikon TE-2000 inverted microscope was used. The imaging system is fitted with two automated 10position filter wheels for both excitation and emission (Sutter Instruments, model Lambda 10-2), an automated dichroic filter cube changer (Nikon), XYZ axis mechanized stage (Prior Scientific, Inc.), a high-resolution 12-bit Orca-100 ER IEEE1394 digital camera (Hamamatsu Inc.), MetaMorph 7.5 image acquisition, processing, and analysis software with three-dimensional reconstruction and point-spread function-based deconvolution capabilities (Universal Imaging/Molecular Devices). Separately addressable excitation, dichroic, and emission filters allow the maximum flexibility for multiple wavelength and ratio imaging in this system.

For imaging metastatic tumors of GFP-expressing 4T1 cells in situ in the intact mouse lung, an established isolated lung microscopy method was utilized [15,21]. Some isolated lungs taken from animals with experimental metastases were perfused with Griffonia simplicifolia lectin conjugated with TRITC (Molecular Probes, Eugene, OR) via the pulmonary artery for 30 minutes to label the pulmonary and the tumor microvasculature. The lungs were placed in a specially designed Plexiglas chamber over a coverslip-window at the bottom with the posterior surface of the lung gently touching the coverslip. Subpleural tumors were directly visualized at high magnification $(\times 600)$ by epifluorescence microscopy using appropriate filters and illumination. Image processing and analysis were performed with MetaMorph software (Molecular Devices, Sunnyvale, CA).

\section{Experimental metastasis model}

A syngeneic breast cancer experimental metastasis model was used in the study as described previously [22]. The 4T1-GFP cell line was derived from the 4T1 mouse mammary adenocarcinoma cell line (\# CRL-2539, ATCC, Manassas, VA) by stable transfection with eGFP (Clontech, Mountain View, CA). We injected young nu/nu mice (Charles River) into the tail-vein with single-cell suspensions of 4 T1-GFP cells at $30 \times 10^{3}$ cells per gram body weight followed by lung isolation, perfusion, and intact organ epifluorescence microscopy up to 21 days after injection. The volume of injected medium with cells was $100 \mu \mathrm{l}$. Animals were monitored on a daily basis for signs of respiratory distress. The research was conducted under a protocol reviewed and approved by the University of South Alabama Institutional Animal Care and Use Committee.

\section{Statistical analysis}

Data analysis was performed using SigmaStat (Systat Software Inc., San Jose, CA) using one-way analysis of variance and Bonferroni's test. Data are expressed graphically as means \pm standard error of the mean (SEM) using SigmaPlot (Systat Software Inc., San Jose, CA). Differences were considered significant with $P<0.05$.

\section{Results \\ Cx43 expression in tumor cell-endothelial cell co-culture in vitro and in pulmonary metastasis in vivo \\ Cx43 is upregulated in tumor cell-endothelial cell contact areas}

Co-culture of 4T1-GFP cells (green cytoplasmic staining with blue nuclei) and PMVECs (blue nuclei without cytoplasmic staining) lead to upregulation of $\mathrm{Cx} 43$ expression (red) at the contact areas between the tumor cells and endothelial cells (Figure 1a, b, c, white arrows). Cells not in a heterologous contact demonstrate baseline expression of $\mathrm{Cx} 43$ (Figure $1 \mathrm{a}$ and $1 \mathrm{~b}$, yellow arrows). An overlay of the differential interference contrast (DIC) image demonstrates the intense expression of $\mathrm{Cx} 43$ in the contact areas (white arrow) between an endothelial cell on the left and a 4T1-GFP cell on the right (Figure 1d). Immunohistofluorescence of a lung metastatic tumor section stained for both $\mathrm{Cx} 43$ (red) and for CD31 (green) with nuclear DAPI staining in blue demonstrates that more than $95 \%$ of endothelial cells within the tumor mass (green) have an increase in $\mathrm{Cx} 43$ staining (Figure 1e, arrows). Immunofluorescence of a fixed mouse lung section after 12 hours of tail vein injection of tumor cells depicts tumor cells lodged inside pulmonary microvasculature with concomitant upregulation of $\mathrm{Cx} 43$ in both the endothelial cells (Figure 1f, white arrow) and the tumor cells (Figure 1f, yellow arrow). 

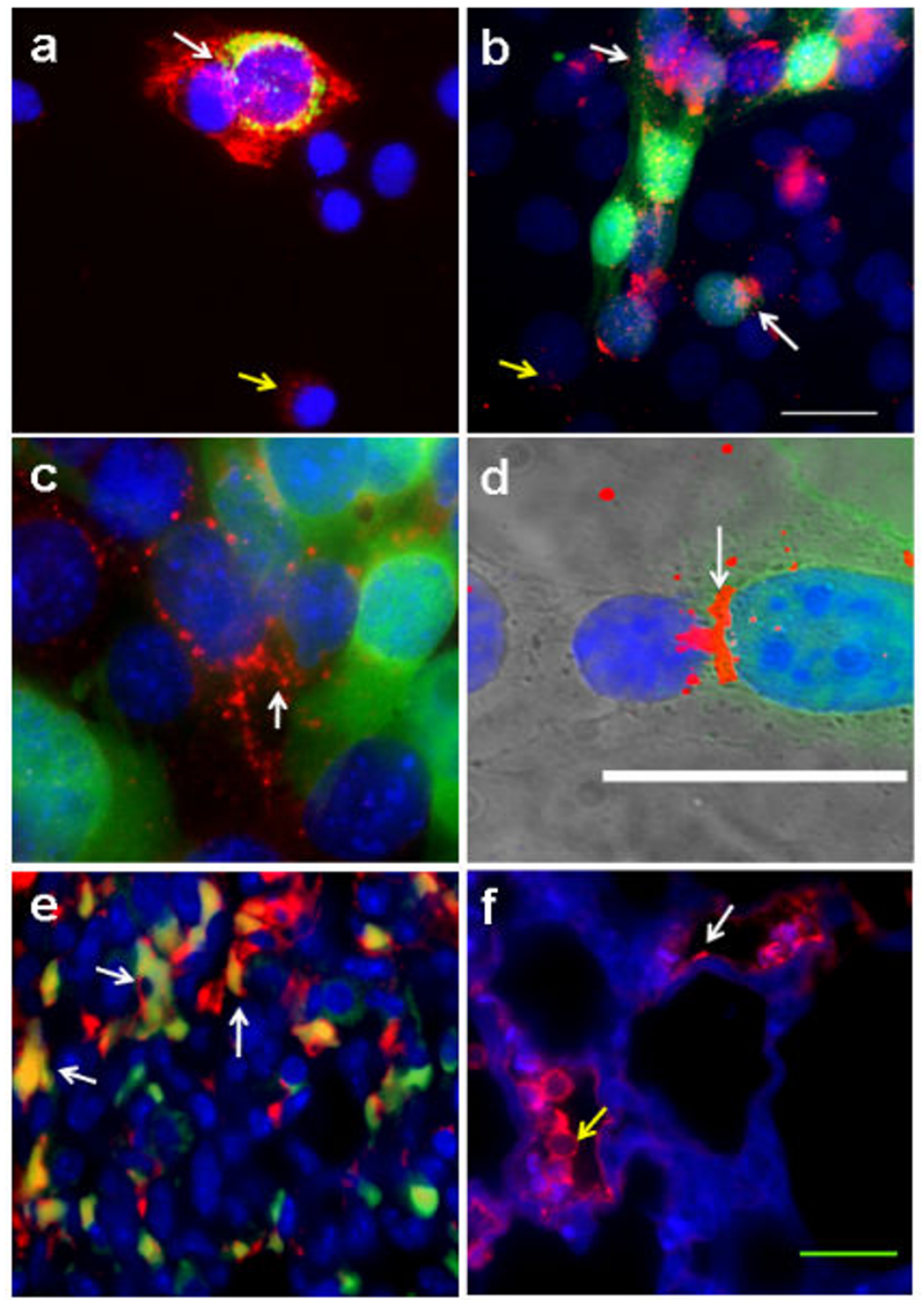

\section{Figure I}

Upregulation of connexin-43 in tumor cell-endothelial cell contact areas in vitro and in vivo. (a)-(d) Immunocytofluorescence detecting connexin-43 (Cx43; red) in co-culture of 4TI-GFP cells (green cytoplasmic staining with blue nuclei) and pulmonary microvascular endothelial cells (PMVECs; blue nuclei without cytoplasmic staining). 4TI-GFP and PMVECs were plated together in co-culture and examined under the green fluorescent protein (GFP) channel (4TI cells), UVchannel (nuclei), and Cy5-channels (Cx43), and shown as an overlay of all channels indicating the location of 4TI-GFP cells (green), nuclei of both cell types (blue), and Cx43 (red). In (a), (b), and (c), upregulation of Cx43 expression (red) is seen at the contact areas between the tumor cells and PMVECs (white arrows). Cells not in a heterologous contact show little expression of Cx43 (yellow arrows). Panel (d) shows an additional overlay of the DIC image to further emphasize the Cx43 intense expression at the areas of contacts (white arrow) between an endothelial cell on the left and a 4TI-GFP cell on the right. (e) Immunohistofluorescence of a lung metastatic tumor section stained for both Cx43 (red) and CD3I (green) with nuclear DAPI staining in blue. Most endothelial cells within the tumor mass (green) showed an increase in Cx43 staining (arrows). (f) Immunohistofluorescence of a fixed mouse lung section after 12 hours of tail vein injection of tumor cells. Autofluorescence of lung tissue in the GFP-channel and the GFP fluorescence of 4TI-GFP cells were assigned the blue pseudocolor for better contrast with the Cy5-channel Cx43 signal (red). Tumor cells can be seen lodged inside pulmonary microvessels. The image clearly indicates the upregulation of $\mathrm{Cx} 43$ in both the endothelial cells (white arrow) and the tumor cells within the vessels adhering to the vessel walls (yellow arrow). The scale bar in (a)-(d) is $10 \mu \mathrm{m}$ and (e), (f) is $25 \mu \mathrm{m}$. 
Upregulation of $\mathrm{Cx}_{x} 43$ marks the sites of micrometastatic foci and metastatic tumor vasculogenesis

Figure 2 demonstrates that $\mathrm{Cx} 43$ expression marks the sites of micrometastases in sections from lungs after tail vein injection of tumor cells. $\mathrm{Cx} 43$ (red) was upregulated in vessels containing control $4 \mathrm{~T} 1$ tumor cells (Figure 2a, yellow arrow), while vessels not containing tumor cells in the same section had barely detectable Cx43 signals (Figure 2a, white arrows). Lung sections with C61S expressing tumor cells exhibited similar pattern of Cx43 expression (Figure 2b), whereas those with the dominant-negative G138R expressing cells exhibited decreased staining for Cx43 (Figure 2c). In contrast, in lung sections with Cx43 overexpressing tumor cells, a significant increase in the number of intravascular tumor cells, an increase in the number of vessels containing adherent tumor cells, and induction of Cx43 were seen (Figure 2d). Ninety five percent of the vessels with $\mathrm{Cx} 43$ staining appeared to contain tumor cells (Figure 2d, yellow arrows). Upregulation of Cx43 in tumor cell-endothelial cell contact areas in one of the larger vessels is shown using DIC (Figure 2e), Cx43 signal (white, Figure 2f), overlay of DIC and $\mathrm{Cx} 43$ signal (Figure 2g) and overlay of GFP (tumor cells, green), DAPI (nuclei, blue), and Cx43 (red, yellow arrows) signals (Figure $2 \mathrm{~h})$.

Intratumor vessels and metastatic foci demonstrate increased Cx43, making Cx43 a potential marker for not only micrometastases, but also for tumor vasculature (Figure 3). Figures $3 \mathrm{a}$ and $3 \mathrm{~b}$ depict lower-magnification images of lung sections containing control 4T1-GFP tumor cells. Cx43 (red) was upregulated in the vessels that contained tumor cells (yellow arrow) while vessels without tumor cells in them had minimal Cx43 signals (white arrows). A metastatic tumor in the lung with a high level of $\mathrm{Cx} 43$ expression in the tumor vasculature is visible in Figure 3c (arrow). Figure 3d shows a higher-magnification image of the same tumor highlighting the region with the high Cx43 signal. Another metastatic tumor at low magnification (Figure 3e) demonstrates Cx43 upregulation within tumor vessels at higher magnification (Figure 3f). Figure $3 \mathrm{~g}$ shows a vessel containing tumor cells and exhibiting strong Cx43 signal (yellow arrow), while a neighboring vessel with a stack of red blood cells (white arrow) but no tumor cells shows no $\mathrm{Cx} 43$ reactivity. A vessel from a control lung treated with non-immune mouse IgG instead of the primary antibody for $\mathrm{Cx} 43$ showed no staining of a vessel (arrow) in which red blood cells can be seen due to their autofluorescence in the GFP channel (Figure 3h).

\section{Role of Cx43 in tumor cell-endothelial cell interaction in vitro \\ Cx43 mediates border-sharing and co-growth of 4TI-GFP cells and PMVECS}

In co-culture, 4T1-GFP and PMVECs form a monolayer where the cancer cells and endothelial cells could not be identified in DIC pictures (Figure 4A-a,b), but their mixed growth can be ascertained by overlaying the cancer cell pictures in the GFP channel (Figure 4A-c,d) with the DIC pictures (overlays shown in Figure 4A-e,f). Co-culture of wild-type 4T1-GFP, C61S, or Cx43OE and PMVECs exhibited the mosaic growth pattern and the presence of shared borders (Figure 5). In contrast, 4T1-GFP cells harboring the mutant G138R grew on top of endothelial cells without integration into the endothelial monolayer (Figure 5), indicating a possible lack of intercellular communication between the two cell types. This suggests that defective gap junctional communication results in inhibition of coordination required for border-sharing and co-growth.

\section{Cx43 mediates establishment of functional GIC between 4TI-GFP cells and PMVECs}

The presence of endogenous $\mathrm{Cx} 43$ was demonstrated in wild-type 4T1 cells where Cx43 is localized mostly at the plasma membrane between the cells (Figure 6A, 4T1, white arrows). The G138R dominant-negative mutant as well as the Cx43 wild-type Cx43OE cell line expressed $\mathrm{Cx} 43$ both at the plasma membrane (white arrows) and in the cytoplasm (yellow arrows). The mutant C61S expressed a non-targetable form of $\mathrm{Cx} 43$ mostly in the cytoplasm (Figure 6A, yellow arrows). Quantification of the immunocytofluorescence signal of $\mathrm{Cx} 43$ in 4T1-GFP cells expressing mutant and wild-type $\mathrm{Cx} 43$ demonstrated an at least two-fold increase in $\mathrm{Cx} 43$ expression compared with endogenous expression (control) or with mock transfection (Figure 6B). Western blot analysis indicated increased expression of $\mathrm{Cx} 43$ forms in transfected cells compared with non-transfected 4T1-GFP cells (Figure $6 \mathrm{C})$. The quantification of bands from three blots illustrates that the transfected cells show an at least a two-fold increase in $\mathrm{Cx} 43$ expression $(P<0.05)$ compared with wild-type 4T1-GFP cells (Figure 6C, bar graph).

When 4T1-GFP cells were placed on top of Calcein Red Orange labeled subconfluent monolayer of endothelial cells, the 4T1-GFP cells established functional gap junctions with the endothelial cells. In tumor cells (green of GFP) that were in close contact with endothelial cells, transfer of Calcein Orange Red from endothelial cells can be observed (red color inside green cells; Figure 7A, 4T1, and Figure $4 \mathrm{~B}$, black bar). Dye transfer was significantly reduced in tumor cells expressing the G138R mutant (Figure 7A, G138R, and Figure 7B, red bar) and in the presence of gap junctional inhibitor $18 \beta$-glycyrrhetinic acid (30 $\mu \mathrm{M}$; Figure $7 \mathrm{~B}$, blue bar). On the other hand, overex- 

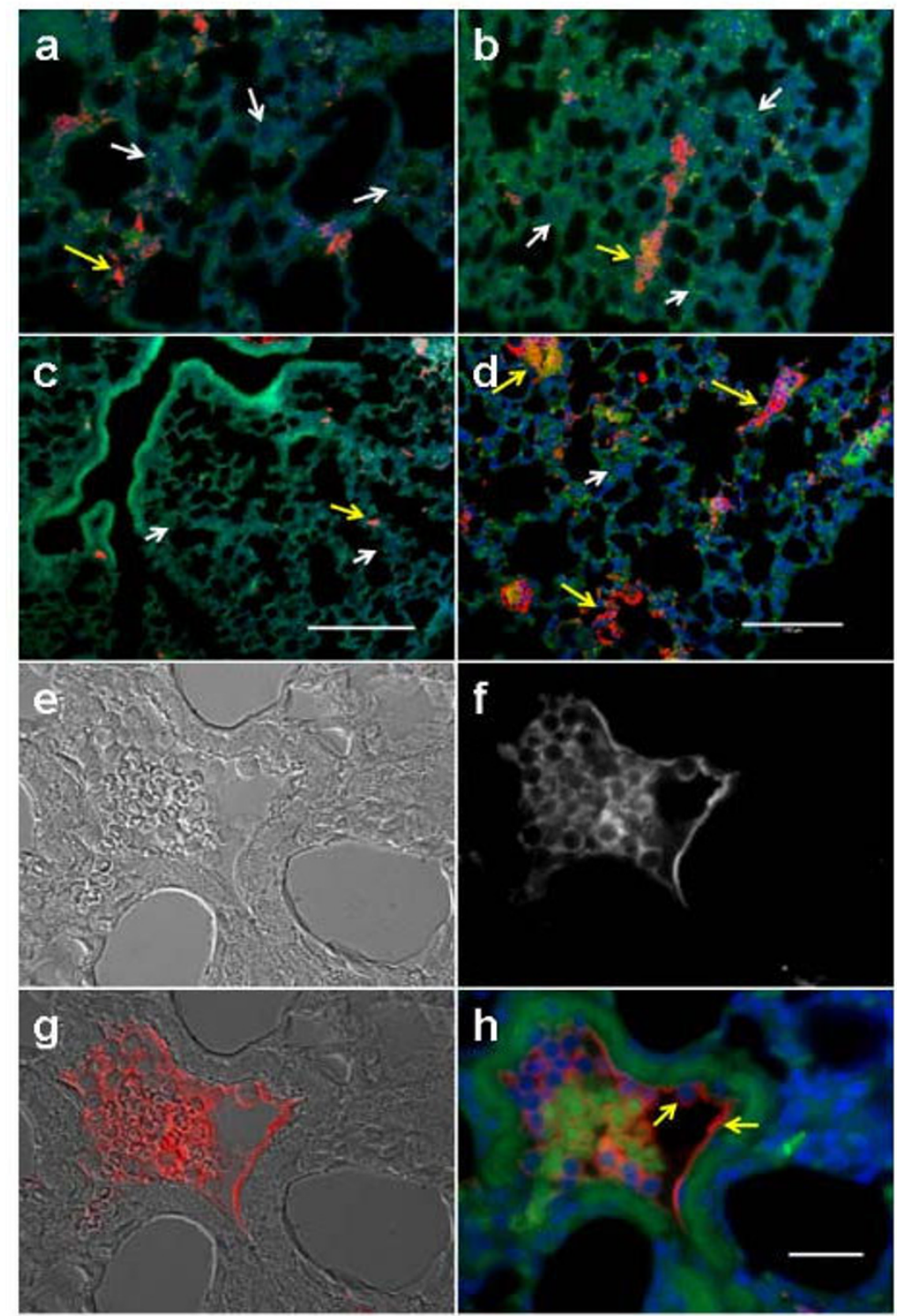

\section{Figure 2}

Connexin-43 expression marks the sites of micrometastases. (a)-(d), (h) Immunohistofluorescence fixed sections of mouse lung after 12 hours of tail vein injection of 4TI-GFP cells or connexin-43 (Cx43) mutant variants C6IS, GI38R, or Cx43OE. Autofluorescence of lung tissue and 4TI-GFP fluorescence (green fluorescent protein (GFP) channel green color) and Cx43 signal (Cy5-channel red color), and nuclear staining (DAPI channel blue color) were overlaid. Panels (a)-(d) show images of lung sections taken at low magnification. Panel (a) shows the sections from a lung after tail vein injection of control 4TI-GFP tumor cells. Cx43 (red) was upregulated in vessels containing tumor cells (yellow arrow), while vessels not containing tumor cells from the same lung had barely detectable Cx43 signal (white arrows). Lung sections with C6IS expressing tumor cells exhibited similar pattern of Cx43 expression (b), whereas those with the dominant-negative GI38R expressing cells exhibited decreased staining of Cx43 (c). In contrast, in lung sections with Cx43 overexpressing tumor cells, a significant increase in the number of intravascular tumor cells, an increase in the number of vessels containing adherent tumor cells, and induction of Cx43 was seen (d). Most of the vessels with Cx43 staining appeared to contain tumor cells (yellow arrows). Panels (e)-(h) show higher-magnification images of lung sections containing tumor cells overexpressing Cx43. Panel (e) shows a DIC image of a vessel within the lung containing tumor cells; ( $f$ ) shows the Cx43 signal in the same vessel; and (g) is an overlay showing the induction of $\mathrm{Cx} 43$ in both endothelium and tumor cells in red color. Panel (h) shows another overlay of the same image of the green (tumor cells, autofluoresence of lung tissue and red blood cells), blue (nuclei), and red (Cy5 for Cx43) channels. Scale bars in (c), (d) are $100 \mu \mathrm{m}$ (the same scale is used in (a) and (b)) and the scale bar in (h) is $25 \mu \mathrm{m}$ (the same scale is used in (e), (f), and (g)). 

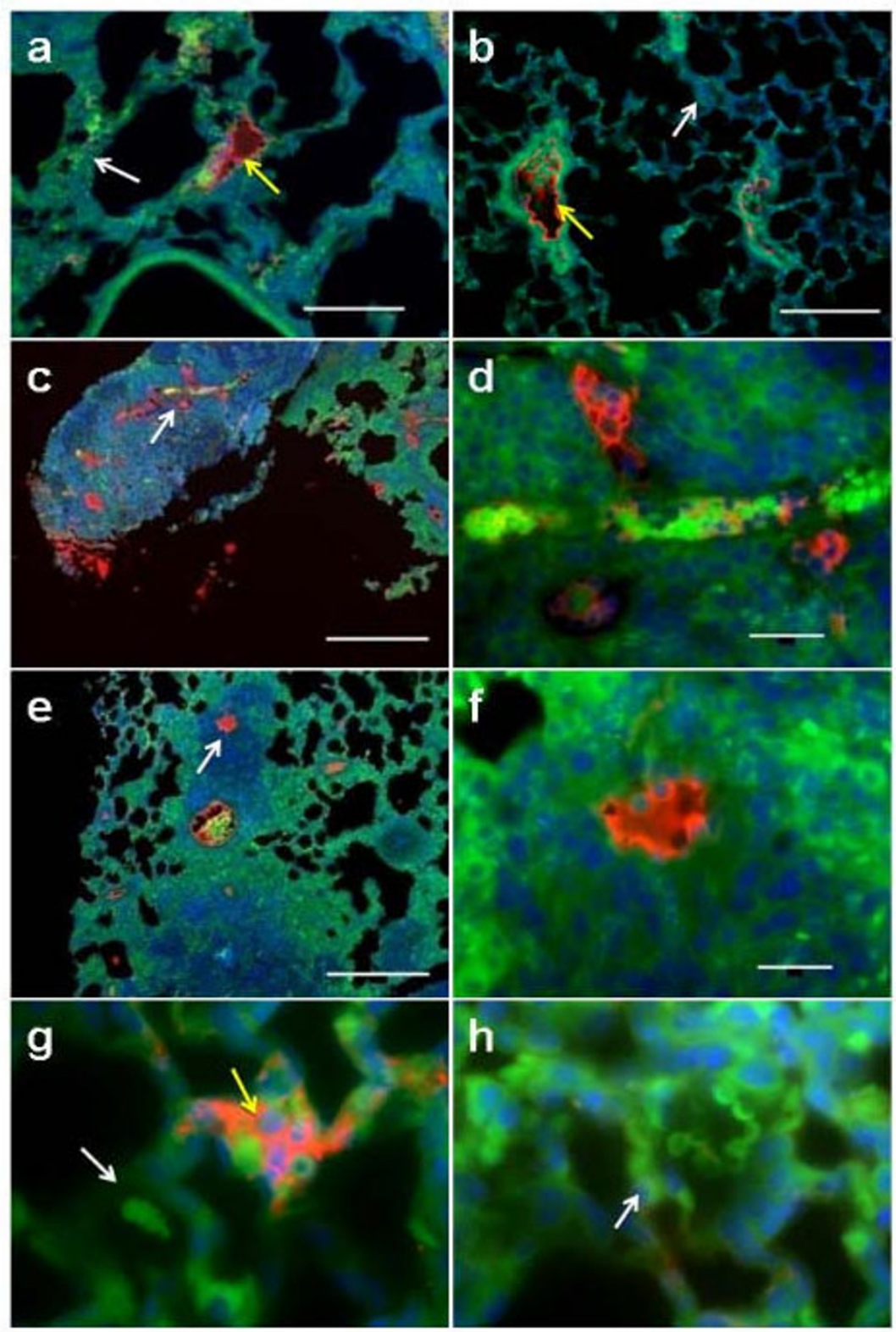

\section{Figure 3}

Intratumor vessels and metastatic foci demonstrate increased connexin-43. Immunohistofluorescence for connexin-43 (Cx43) of mouse lung sections 12 days after tail vein injection of 4TI-GFP control cells or of cells expressing Cx43 variants C6IS, GI38R, or Cx43OE. Lung tissue autofluorescence and tumor cell green fluorescent protein (GFP) fluorescence is pseudocolored green color and the Cx43 signal (Cy5-channel) is shown in red. Nuclear staining with DAPI is shown in blue. Each picture is an overlay of these three channels. (a), (b) Lower-magnification images of lung sections containing control 4TIGFP tumor cells. Cx43 (red) was upregulated in the vessels that contained tumor cells (yellow arrow) while vessels without tumor cells in them had minimal Cx43 signal (white arrows). (c) A metastatic tumor in the lung with enriched Cx43 signal associated with the tumor vasculature. (d) A higher-magnification image of the same tumor highlighting the region with the high Cx43 signal. (e) Another metastatic tumor with (with a higher-magnification image in (f)) demonstrating the Cx43 upregulation within tumor vessels. (g) One vessel containing tumor cells and exhibiting high Cx43 signal (yellow arrow), while a neighboring vessel with a stack of red blood cells (white arrow) but no tumor cells shows no Cx43 reactivity. (h) A vessel from a control lung with non-immune mouse IgG used in place of the primary antibody showing no staining of a vessel (arrow) in which red blood cells can be seen due to their autofluorescence in the GFP channel. The scale bar in (a), (b), (c), and (e) is $100 \mu \mathrm{m}$ and the scale bar in (d) and (f) (which are to the same scale as $(g)$ and (h)) is $25 \mu \mathrm{m}$. 

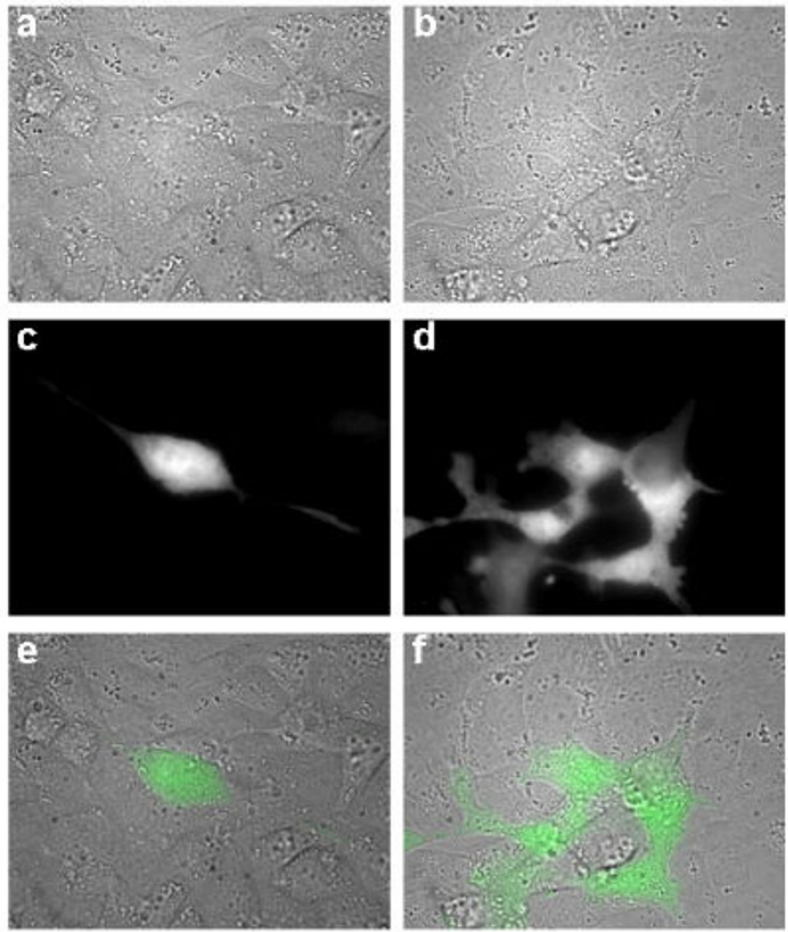

\section{Figure 4}

Tumor cells and endothelial cells share common borders in vitro. (a), (b) 4TI-GFP and pulmonary microvascular endothelial cells were plated together in co-culture and examined by DIC imaging. (c), (d) The same fields were imaged in the green fluorescent protein (GFP) channel to reveal the presence of the 4TI-GFP cells. (e), (f) The images were overlaid to show the location and shared borders between the tumor cells and the endothelial cells.

pressing wild-type $\mathrm{Cx} 43$ enhanced dye transfer (Figure 7A, $\mathrm{Cx} 43 \mathrm{OE}$, and Figure $7 \mathrm{~B}$, green bar). The expression of C61S mutant did not affect dye transfer via endogenous Cx43 (Figure 7A, C61S, and Figure 7B, yellow bar).

Immunostaining revealed the presence of $\mathrm{Cx} 43$ at the contact area of some tumor cells that were attached to the apical surface of underlying endothelial cells (Figure 10A).

\section{Role of Cx43 in the metastatic efficiency}

\section{Cx43 facilitates tumor cell adhesion to lung endothelium}

A role for $\mathrm{Cx} 43$ in tumor cell attachment to the pulmonary endothelium in vivo is demonstrated by the following observations. Cx43 expression, detected by immunofluorescence (red pseudocolor), was upregulated in the tumor cells and in the endothelium of the vessels with control tumor cells (Figure 8, 4T1). Tumor cells with C61S mutation showed similar levels of Cx43 expression in the endothelium as for control cells (Figure 8). In both cases, the number of arrested cells within the vasculature

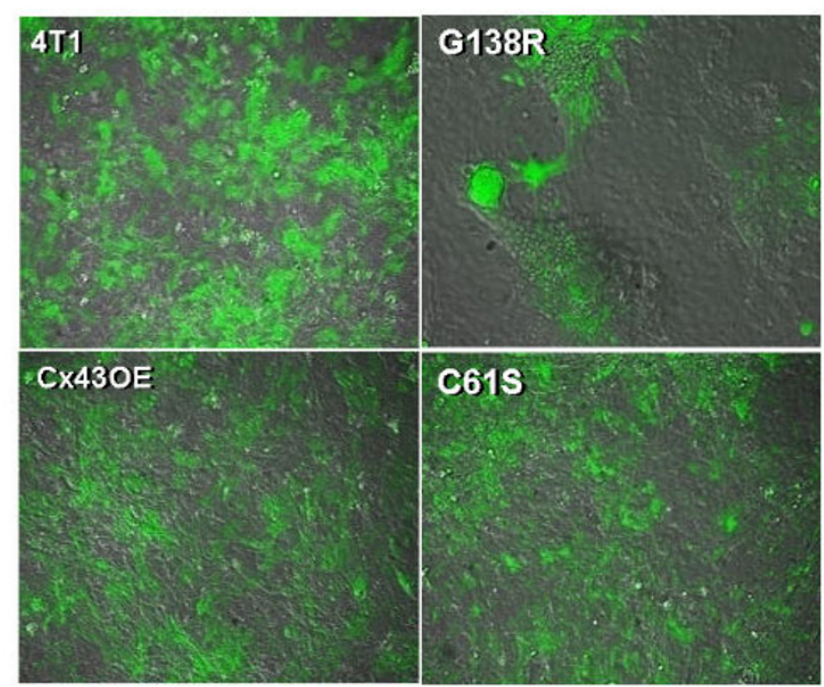

\section{Figure 5}

Patterns of co-growth of 4T I-GFP breast cancer cells (in green) and pulmonary microvascular endothelial cells (DIC channel, gray) in vitro. Co-culture of wild-type 4TI-GFP cells (4TI), Cx43-C6IS mutation expressing 4TIGFP cells (C6IS), and connexin-43 overexpressing cells (Cx43OE), and pulmonary microvascular endothelial cells exhibited side-by-side growth and shared borders. In contrast, 4TI-GFP cells expressing the mutant Cx43-GI38R (GI38R) grew on top of endothelial cells without integration into the monolayer.

was similar. Fewer cells with the G138R mutation were found arrested (Cx43 signal in red; Figure 8). In contrast, lung vasculature containing 4T1-Cx43OE tumor cells showed intense $\mathrm{Cx} 43$ staining of the endothelium and the tumor cells (Figure 8). There were also significantly more tumor cells in the blood vessels of these lungs. These data indicate a cell adhesion role for functional $\mathrm{Cx} 43$ in breast cancer metastasis to the lung in this syngeneic model. Similar results were obtained with immunohistochemical analysis of lung tissue sections containing metastatic tumors of the variant Cx43 4T1-GFP cell lines. Figure 9A, $4 \mathrm{~T} 1$, depicts a vessel containing red blood cells and dark nuclei of adherent control 4T1-GFP cells within it. The number of vessel-adherent tumor cells expressing the C61S mutation was comparable to that for control cells (Figure 9A). On the other hand, the number of adherent tumor cells with the G138R mutated Cx43 was significantly lower (Figure 9A, G138R). Tumor cells overexpressing Cx43 appear to populate the vessels in much greater numbers (Figure 9A, Cx43OE). Quantification of the tumor cell numbers adhering to the lung endothelium shows that dominant negative G138R expression reduced the number of arrested tumor cells (Figure 9B, red bar), while overexpressing wild-type $\mathrm{Cx} 43$ increased the 
A
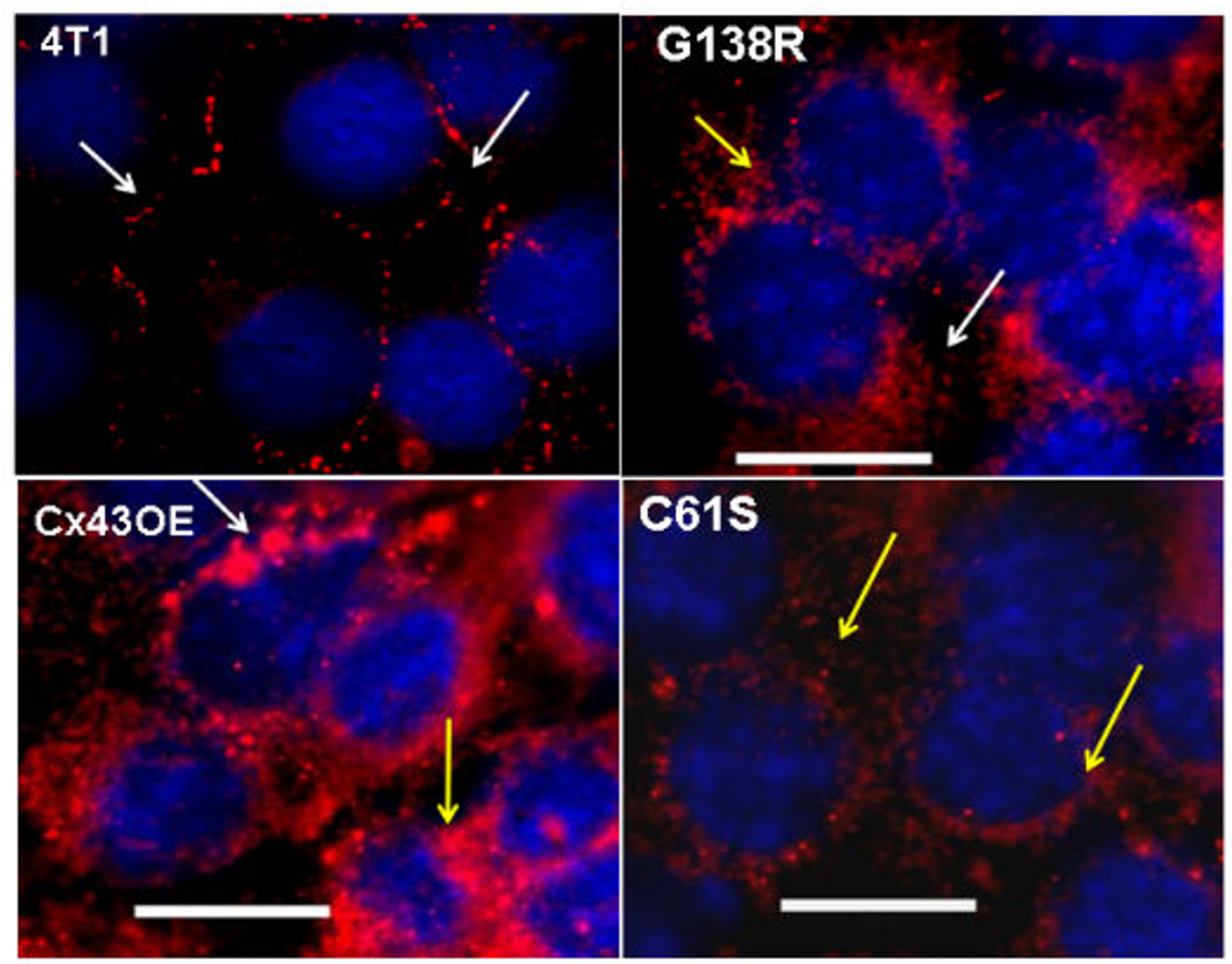

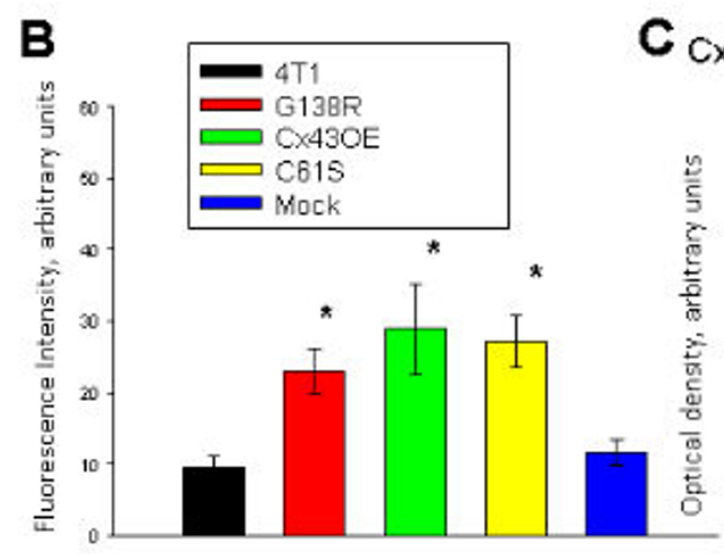

B
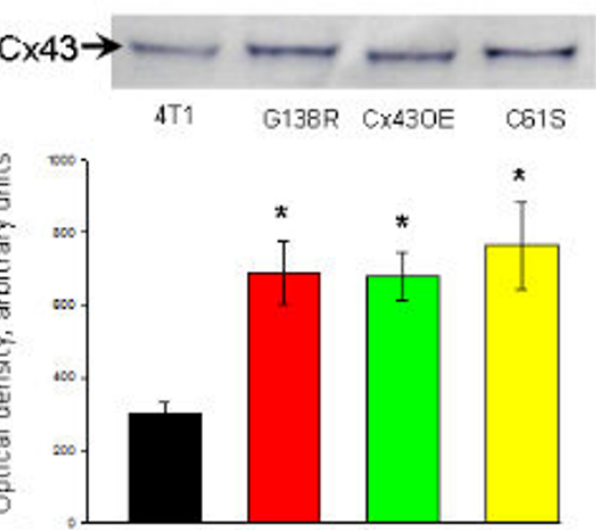

\section{Figure 6}

Expression of connexin-43 by the mutant variants. (A) Immunocytofluorescence analysis of connexin-43 (Cx43) expression in wild-type 4TI-GFP tumor cells and in 4TI-GFP cells transfected with expression vectors of the mutant GI38R and C6IS in addition to a vector expressing two copies of wild-type Cx43 (Cx43OE). Endogenous Cx43 in wild-type 4TI-GFP cells is present mostly at the plasma membrane between the cells (3A, 4TI, white arrows). The GI38R dominant-negative mutant was expressed both at the plasma membrane (white arrows) and in the cytoplasm (yellow arrow). Wild-type overexpression led to upregulation of $\mathrm{Cx}_{x} 43$ in both the plasma membrane (white arrows) and in the cytoplasm (yellow arrows, 3A, Cx43OE). Cx43 with the C6IS mutation was mostly in the cytoplasm (yellow arrows, 3A, C6IS). (B) Quantification of the immunocytofluorescence signal of $\mathrm{Cx} 43$ in 4TI-GFP cells expressing mutant and wild-type Cx43. All of the transfectants showed at least a factor or two more $\mathrm{C} \times 43$ expression compared with endogenous expression (control) or with mock transfection. (C) Western blot analysis showing increased expression of $\mathrm{Cx} 43$ forms in transfected cells when compared with non-transfected 4TI-GFP cells. The quantification of bands from three blots illustrates that the transfected cells show an at least two-fold increase in Cx43 expression compared with wild-type 4TI-GFP cells. *P $<0.05$. 

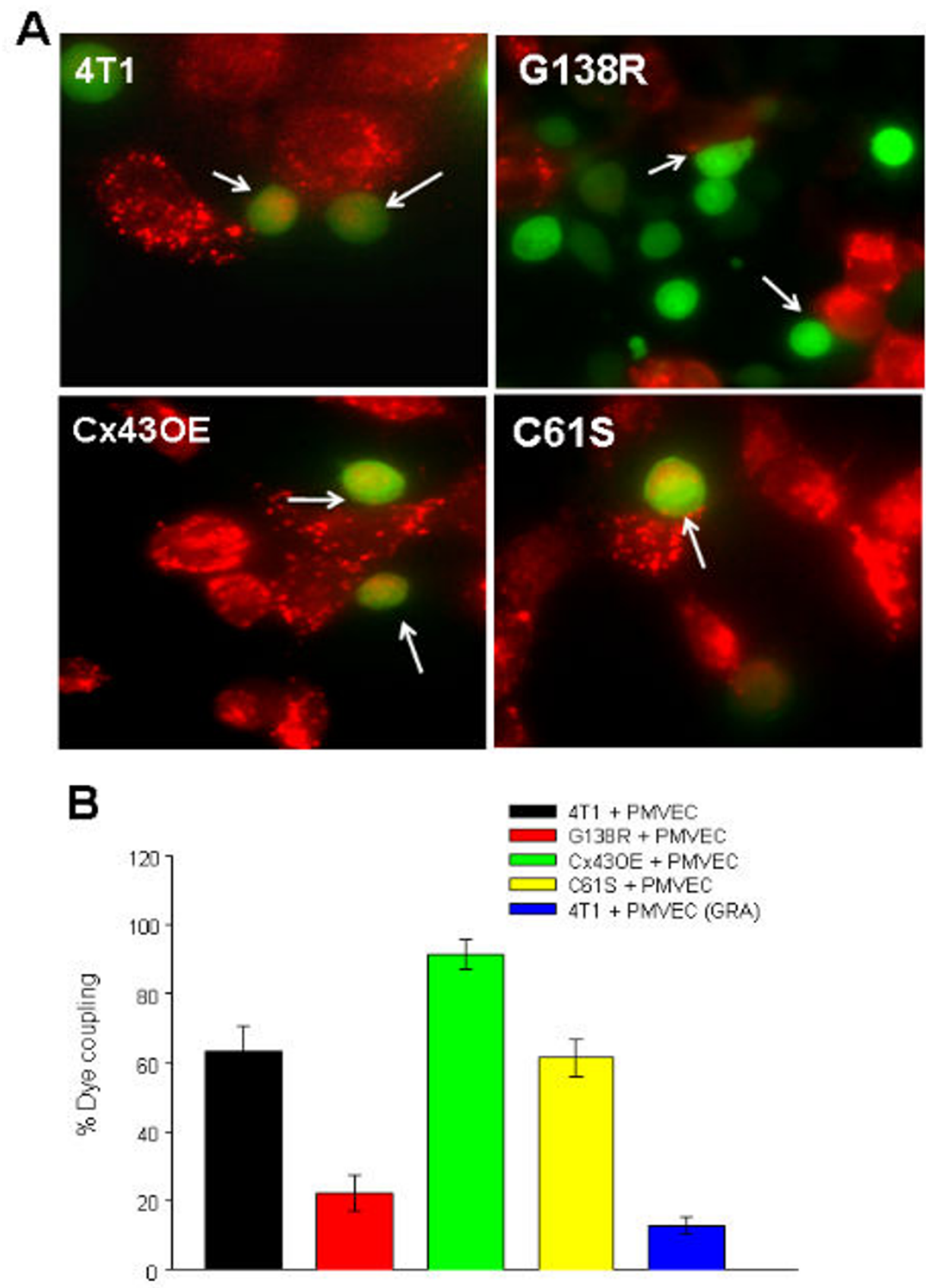

\section{Figure 7}

Dye transfer between 4T I-GFP and pulmonary microvascular endothelial cells. (A) Subconfluent monolayers of pulmonary microvascular endothelial cells in coverglass-bottomed dishes was labeled with $5 \mu M$ Calcein Red AM and then thoroughly washed for removal of extracellular dye. 4TI-GFP cells with or without connexin-43 (Cx43) mutation variants were deposited into the dish and placed in a cell culture incubator. After I hour, the cells were imaged in the red (for Calcein Red) and green fluorescent protein (GFP) channels and the pictures were overlaid. In tumor cells (green) that were in close contact with endothelial cells, transfer of Calcein Red can be observed (red color inside green cells). (B) Quantification of 4TIGFP cells exhibiting dye transfer from endothelial cells. Dye transfer was significantly reduced in 4TI-GFP tumor cells expressing the GI38R Cx43 mutant (red bar) and in the presence of gap junctional inhibitor I8ß-glycyrrhetinic acid (30 $\mu M$ ) (blue bar). On the other hand overexpressing wild-type Cx43 enhanced dye transfer (green bar). The expression of C6IS mutant did not seem to affect dye transfer (yellow bar). 


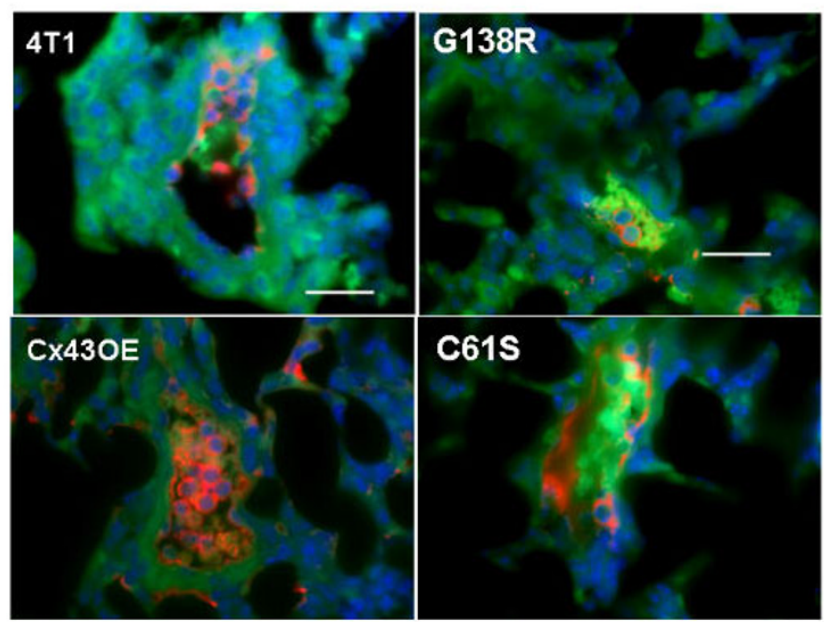

Figure 8

Role of connexin-43 in tumor cell attachment to lung endothelium. Immunofluorescence for connexin-43 (Cx43) of mouse lung sections 12 hours after tail vein injection with 4TI-GFP control cells or cells expressing Cx43 variants C6IS, GI38R, or Cx43OE. Autofluorescence of lung tissue and red blood cells in the green fluorescent protein (GFP) channel (green), Cx43 signal in the Cy5 channel (red), and the nuclear DAPI signal (blue) were overlaid. Panel '4TI' (control 4TI-GFP): Cx43 (red) was upregulated in the tumor cells and in the endothelium of the vessels with tumor cells. Panel 'C6IS': tumor cells with C6IS mutation, showing similar level of Cx43 expression as for control cells. Panel 'GI38R': cells with dominant negative GI38R mutation, showing Cx43 (red) around a few tumor cells within the vessels with a limited number of tumor cells in the vessels. In contrast lung segments containing 4TI tumor cells overexpressing Cx43 show intense Cx43 staining and the vessels contained large number of tumor cells (see panel 'Cx43OE'). The scale bar is $25 \mu \mathrm{m}$ for all panels.

number of arrested tumor cells within the lung vasculature (Figure 9B, green bar).

\section{Discussion}

Although a variety of connexins are involved in GJIC in different cell types, the expression of $\mathrm{Cx} 43$ in vascular endothelial cells and in many tumor cell lines indicates a primary role for this protein in the heterologous gap junctional communication during tumor cell-endothelial cell interaction [23-28]. Functional GJIC between tumor cells and vascular endothelial cells mediated via $\mathrm{Cx} 43$ has been demonstrated $[9,23,25]$. Consequently, it was also shown that quantitative and qualitative changes in connexin expression are associated with tumor progression, proliferation, invasion, and metastasis [9,25,29]. Cx43 enhanced the adhesiveness and mediated the invasion in malignant gliomas [20]. In addition, the increased expression of specific connexins correlated with increased inva- siveness of lung squamous cell carcinoma or NIH3T3-Ras cells $[29,30]$ and Cx43 expression was upregulated in urethane-induced mouse lung adenomas [31]. Increased levels of Cx43 mRNA was found in hepatocellular carcinoma tissues [32] and in the stroma of multiple intestinal neoplasia-mice adenomas [23]. Expression of $\mathrm{Cx} 43$ in mammary carcinoma cell lines lacking endogenous $\mathrm{Cx} 43$ enabled the formation of heterocellular GJIC with microvascular endothelial cells and increased their diapedesis [12]. Increased cytosolic and plasma membrane expression of $\mathrm{Cx} 43$ in lymph node metastases of breast cancer was demonstrated [11]. Cx43 was detectable in normal lung, smaller size tumor, and larger size mouse lung tumors [24]. Our study shows a role for $\mathrm{Cx} 43$ in breast cancer metastasis to the lung in a syngeneic, murine experimental metastasis model.

Although connexins are classically considered as gapjunctional proteins, non-junctional roles for connexins in hemichannels with ion-channel-like functions or possessing channel-independent, signaling-type functions have received considerable attention recently $[33,34]$. Adhesion-mediated establishment of functional GJIC between lung-metastatic B16F10 melanoma cells and endothelium has been shown to be dependent on the expression of Cx43 in both cell partners [35].

The major conclusion of this study is that gap junctional communication via $\mathrm{Cx} 43$ facilitates metastatic homing by increasing the arrest of cancer cells in the lung vasculature. The reduced attachment of cancer cells with the dominant-negative G138R that allows formation of gap-junction plaques but not of functional junctions suggests a positive correlation between the loss of intercellular communication and the number of adherent tumor cells in the lungs. The idea that the formation of functional gap junctions between a cancer cell and the endothelial cell is critical for tumor cell adhesion to the pulmonary endothelium is novel. Normal gap junction plaques are found in the lateral membranes of cells, below the level of the tight junction belt. In the case of heterologous gap junction formation with adherent cells, the apical surface of the endothelial cells comes into contact with the surface of cancer cells (Figure 10). Therefore, a role for connexins in heterologous adhesion or in establishment of functional GJIC would require the presence of connexins at the apical surface of endothelial cells, as demonstrated for $\mathrm{Cx} 43$ in Figure 10A. Very high concentration of $\mathrm{Cx} 43$ has been demonstrated at the apical surface of epithelial cells [36]. The residual coupling between Cx43G138R expressing tumor cells and endothelial cells expressing wild-type Cx43 in comparison to $18 \beta$-glycyrrhretinic acid treated cells (Fig 7B red and blue bars) is mediated through heterotypic Cx43G138R-Cx43WT channels. These channels were recently described as strongly inhib- 

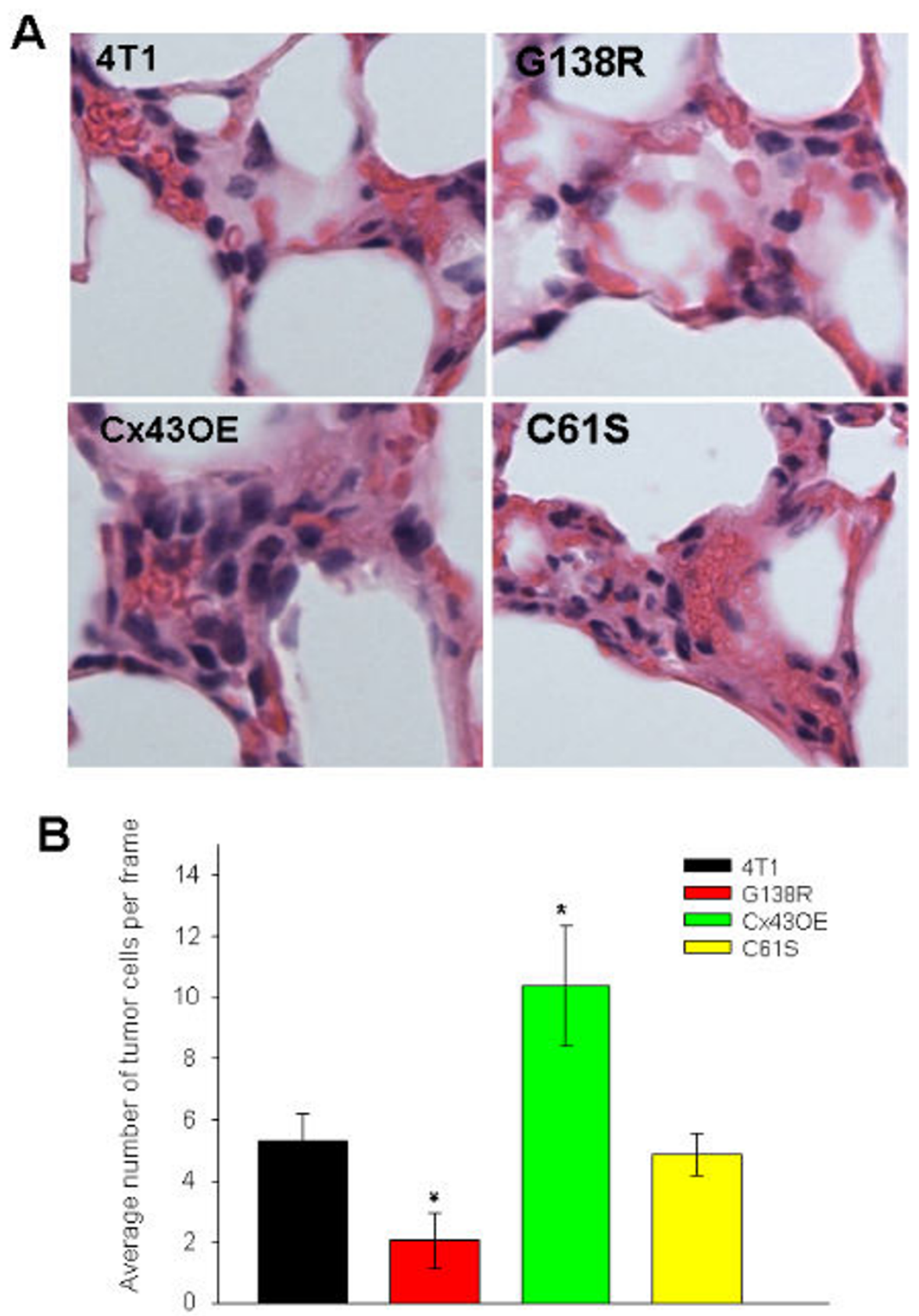

\section{Figure 9}

Connexin 43 facilitates tumor cell attachment to lung endothelium. (A) Hematoxylin-eosin staining of mouse lung sections 12 hours after tail vein injection with 4TI-GFP control cells or cells expressing connexin-43 (Cx43) variants C6IS, GI38R, or Cx43OE. Panel '4TI': a vessel containing red blood cells and dark nuclei of adherent 4TI-GFP control cells within it. Panel 'C6IS': C6IS expressing tumor cells show a comparable density of tumor cell nuclei in blood vessels. Panel 'GI38R': dominant-negative GI38R expressing tumor cells show a decreased number of tumor cells inside vessels. In contrast, tumor cells overexpressing Cx43 appear to populate the vessels in much larger number (see panel 'Cx43OE'). (B) Quantification of the tumor cell numbers adhering to the lung endothelium showing that dominant-negative expression $\mathrm{Cx} 43$ reduced the number of the tumor cells within the vessels in the lung (red bar), while overexpressing wild-type Cx43 resulted in more tumor cells within the lung vasculature (black bar). $* P<0.05$ versus 4 TI. The results represent three lungs for each condition, four slides per lung, and 20 contiguous picture frames per slide. 


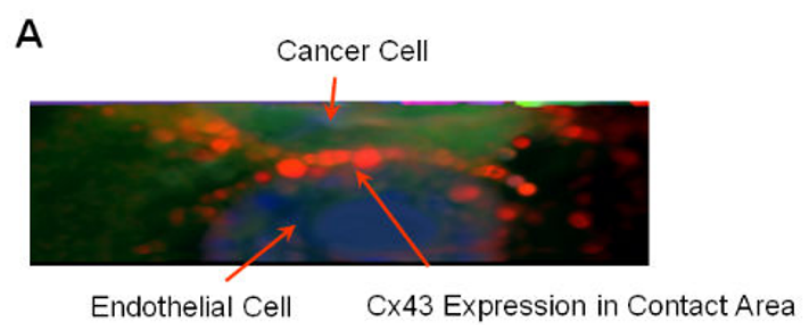

B

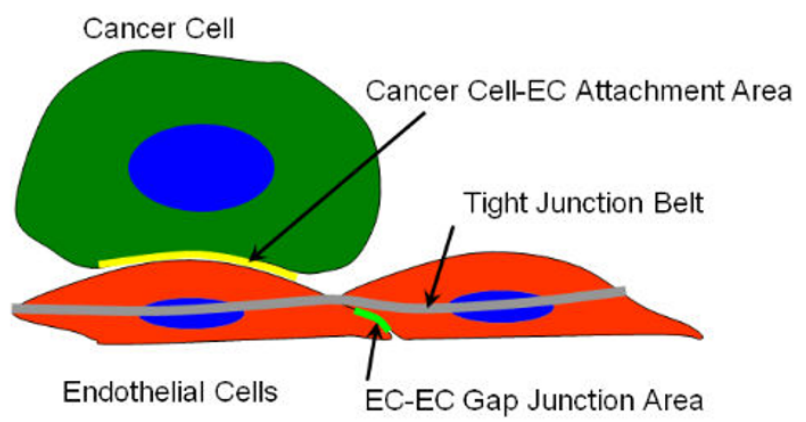

Figure 10

Apical endothelial cell connexin $\mathbf{4 3}$ forms heterologous gap junctions. (A) Connexin-43 (Cx43) localization at the interface between the endothelial apical surface and the 4TI-GFP cell coupling surface. The picture shows a side view of a 4TI-GFP cell sitting on top of an endothelial cell in culture. The side view was generated from a three-dimensional reconstructed image from a stack of $20 \mathrm{z}$-axis optical sections of the cells. (B) Model of cancer cell attachment to endothelial cells. The gap junctional coupling mediated via Cx43 would require its localization on the surfaces in contact: the apical surface of the endothelial cells and the coupling surface of the cancer cell. Our results suggest that the initial attachment mediated via the classical cell adhesion

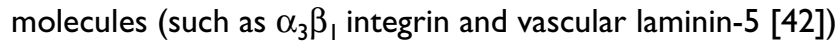
may not be sufficient for retention of the cells and the creation of metastatic foci. This requires establishment of functional gap junctions between the apposing surfaces brought together by cell adhesion molecules. In our model, the required molecule playing an important role in the adhesion efficiency is Cx43, as demonstrated by the loss of adhesion with gap junctional intercellular communication incompetent GI38R mutant variant in the cancer cell alone. How the communication helps the establishment of the metastatic foci is unknown at present, but we speculate that the coordination between the disparate cell types helps them to recognize each other as partners and makes them grow together to become a tumor mass with blood supply.

ited but not completely abolished in their function [37]. The decreased attachment efficiency with the G138R mutation might also be the result of alteration in conformation of the $\mathrm{Cx} 43$ protein. The C61S mutant does not express the mutated $\mathrm{Cx} 43$ in the membrane; therefore, it did not alter the cell adhesion mediated by endogenous $\mathrm{Cx} 43$. The increased adhesion of cancer cells with overexpression of wild-type $\mathrm{Cx} 43$ further confirms the role for Cx43 in tumor cell attachment efficiency as a result of enhanced GJIC.

The marked upregulation of $\mathrm{Cx} 43$ in tumor cell-endothelial cell contact areas, whether in preexisting 'homing' vessels or in newly formed tumor vessels, indicates that $\mathrm{Cx} 43$ can serve as a marker of micrometastases and tumor vasculogenesis. This raises the possibility of a role for $\mathrm{Cx} 43$ in the early incorporation of endothelial cells into prehypoxia size tumors as seeds for vasculogenesis.

Cx43 has been shown to enhance angiogenesis in vitro [38]. Tube formation by human umbilical vein endothelial cells cocultured with $\mathrm{Cx} 43$-transfected malignant glioma cells or with naturally $\mathrm{Cx} 43$-expressing malignant glioma cells was significantly increased compared with tube formation by endothelial cells alone [5]. In addition, upregulation of $\mathrm{Cx} 43$ in the hypertrophic myocardium in mice suggested its role in cardiac angiogenesis [38]. These reports are consistent with our finding of upregulation of Cx43 in cancer cell-endothelial cell contact areas. This selective upregulation of $\mathrm{Cx} 43$ can be exploited as a marker for sites of intravascular metastases as well as for vasculogenic loci within metastatic tumors. Previously, it had been shown that $\mathrm{Cx} 43$ mRNA in normal tissue surrounding lung tumor may act as a molecular marker of nodal micrometastasis in non-small cell lung cancer [39].

The association between cancer and the lack of communication between cancer cells set the stage for a role of dysfunctional gap junctions in carcinogenesis nearly 40 years ago [40]. Since then, both increased and decreased levels of various connexins shown in different models of primary and metastatic tumors had generated multiple interpretations [41]. The difficulty in developing a unified hypothesis regarding the role of connexins in primary and secondary carcinogenesis may be associated with a multiplicity of contradictory functions that the metastatic cell has to perform during intravasation and distant localization. A recent review predicted that "a gain of function (of gap junctions) may characterize the metastatic stage" [41]. Our results confirm this prediction and we hope that they will set the stage for a renewed assessment of the role of connexins in metastatic tumorigenesis and tumor vasculogenesis.

\section{Conclusion}

Cx43 facilitates metastatic 'homing' by increasing adhesion of cancer cells to the lung endothelial cells. The marked upregulation of $\mathrm{Cx} 43$ in tumor cell-endothelial cell contact areas, whether in preexisting 'homing' vessels 
or in newly formed tumor vessels, suggest that $\mathrm{Cx} 43$ can serve as a potential marker of micrometastases and tumor vasculature and that it may play a role in the early incorporation of endothelial cells into small tumors as seeds for vasculogenesis.

\section{Competing interests}

The authors declare that they have no competing interests.

\section{Authors' contributions}

MKE carried out the fluorescence imaging, immunofluorescence, experimental metastatic tumor development in the nude mice, organized the data, and drafted the manuscript. AH generated experimental metastatic tumors in the nude mice. KW generated the C61S and Cx43OE constructs. RD generated the G138R construct and revised the manuscript. MNG participated in the design of the study and revised the manuscript. ABA conceived of the study, participated in its design and coordination, drafted and revised the manuscript. All authors have read and approved the manuscript.

\section{Acknowledgements}

This work was supported by NIH P50 AT00428-0I Project 3 (ABA) and the German Research Association (SFB 645, project B2 to KW)

\section{References}

I. Hotz-Wagenblatt A, Shalloway D: Gap junctional communication and neoplastic transformation. Crit Rev Oncog 1993, 4:54I-558.

2. Eghbali B, Kessler JA, Reid LM, Roy C, Spray DC: Involvement of gap junctions in tumorigenesis: transfection of tumor cells with connexin 32 cDNA retards growth in vivo. Proc Natl Acad Sci USA I99I, 88:1070I-10705.

3. Saunders MM, Seraj MJ, Li Z, Zhou Z, Winter CR, Welch DR, Donahue $H$ J: Breast cancer metastatic potential correlates with a breakdown in homospecific and heterospecific gap junctional intercellular communication. Cancer Res 2001, 6I:1765-1767

4. Carystinos GD, Bier A, Batist G: The role of connexin-mediated cell-cell communication in breast cancer metastasis. J Mammary Gland Biol Neoplasia 200I, 6:43 I-440.

5. Zhang W, DeMattia JA, Song H, Couldwell WT: Communication between malignant glioma cells and vascular endothelia cells through gap junctions. J Neurosurg 2003, 98:846-853.

6. McLachlan E, Shao Q, Laird DW: Connexins and gap junctions in mammary gland development and breast cancer progression. J Membr Biol 2007, 2 I 8:107-I2I.

7. Ito A, Koma Y, Uchino K, Okada T, Ohbayashi C, Tsubota N, Okada $M$ : Increased expression of connexin 26 in the invasive component of lung squamous cell carcinoma: significant correlation with poor prognosis. Cancer Lett 2006, 234:239-248.

8. Saito-Katsuragi M, Asada H, Niizeki H, Katoh F, Masuzawa M, Tsutsumi M, Kuniyasu H, Ito A, Nojima $H$, Miyagawa S: Role for connexin 26 in metastasis of human malignant melanoma: communication between melanoma and endothelial cells via connexin 26. Cancer 2007, I 10:1162-1 | 72 .

9. Ito A, Katoh F, Kataoka TR, Okada M, Tsubota N, Asada $\mathrm{H}$, Yoshikawa K, Maeda S, Kitamura Y, Yamasaki H, Nojima H: A role for heterologous gap junctions between melanoma and endothelial cells in metastasis. I Clin Invest 2000, I 05: I I 89- I I 97.

10. Omori Y, Li Q, Nishikawa Y, Yoshioka T, Yoshida M, Nishimura T, Enomoto K: Pathological significance of intracytoplasmic connexin proteins: implication in tumor progression. J Membr Biol 2007, 2 1 8:73-77.

II. Kanczuga-Koda L, Sulkowski S, Lenczewski A, Koda M, Wincewicz A Baltaziak M, Sulkowska M: Increased expression of connexins 26 and 43 in lymph node metastases of breast cancer. J Clin Pathol 2006, 59:429-433.

12. Pollmann MA, Shao Q, Laird DW, Sandig M: Connexin 43 mediated gap junctional communication enhances breast tumor cell diapedesis in culture. Breast Cancer Res 2005, 7:R522-R534.

13. Al-Mehdi AB, Schaphorst KL, Stevens T: Lung endothelial cell heterogeneity and the microvasculature. In Encyclopedia of the Microvasculature Edited by: Garcia JGN. Amsterdam: Elsevier; 2005:465-470

14. Al-Mehdi AB, Patel M, Haroon A, Reed D, Ohlsson-Wilhelm B, Muirhead K, Gray BD: Increased depth of cellular imaging in the intact lung using far-red and near-infrared fluorescent probes. Int J Biomed Imag 2006, 2006:37470-37477.

15. Al-Mehdi AB, Tozawa K, Fisher AB, Shientag L, Lee A, Muschel RJ: Intravascular origin of metastasis from the proliferation of endothelium-attached tumor cells: a new model for metastasis. Nat Med 2000, 6:100-102

16. Wong CW, Song C, Grimes MM, Fu W, Dewhirst MW, Muschel RJ, Al-Mehdi AB: Intravascular location of breast cancer cells after spontaneous metastasis to the lung. Am J Pathol 2002, 161:749-753.

17. Gong XQ, Shao Q, Langlois S, Bai D, Laird DW: Differential potency of dominant negative connexin 43 mutants in oculodentodigital dysplasia. J Biol Chem 2007, 282:19190-19202.

18. Dobrowolski R, Sommersh of A, Willecke K: Some oculodentodigital dysplasia-associated cx43 mutations cause increased hemichannel activity in addition to deficient gap junction channels. J Membr Biol 2007, 21 9:9-17.

19. McLachlan E, Manias JL, Gong XQ, Lounsbury CS, Shao Q, Bernier SM, Bai D, Laird DW: Functional characterization of oculodentodigital dysplasia-associated Cx43 mutants. Cell Commun Adhes 2005, I 2:279-292.

20. Lin JH, Takano T, Cotrina ML, Arcuino G, Kang J, Liu S, Gao Q, Jiang $\mathrm{L}$, Li F, Lichtenberg-Frate $\mathrm{H}$, Haubrich S, Willecke K, Goldman SA Nedergaard M: Connexin 43 enhances the adhesivity and mediates the invasion of malignant glioma cells. I Neurosci 2002, 22:4302-43II.

21. Al-Mehdi AB, Zhao G, Dodia C, Tozawa K, Costa K, Muzykantov V, Ross C, Blecha F, Dinauer M, Fisher AB: Endothelial NADPH oxidase as the source of oxidants in lungs exposed to ischemia or high K+. Circ Res 1998, 83:730-737.

22. Haroon AT, Patel M, Al-Mehdi AB: Lung metastatic load limitation with hyperbaric oxygen. Undersea Hyperb Med 2007 34:83-90.

23. Husoy T, Knutsen HK, Cruciani V Olstorn HB, Mikalsen SO, Loberg $\mathrm{EM}$, Alexander J: Connexin43 is overexpressed in $\mathrm{Apc}(\mathrm{Min} /+)$ mice adenomas and colocalises with COX-2 in myofibroblasts. Int / Cancer 2005, I I 6:35 I-358.

24. Udaka N, Miyagi $Y$, Ito T: Connexin expression in mouse lung tumor. Cancer Lett 2007, 246:224-229.

25. Tate AW, Lung T, Radhakrishnan A, Lim SD, Lin X, Edlund M Changes in gap junctional connexin isoforms during prostate cancer progression. Prostate 2006, 66: | 9-31.

26. Nagasawa K, Chiba H, Fujita H, Kojima T, Saito T, Endo T, Sawada N: Possible involvement of gap junctions in the barrier function of tight junctions of brain and lung endothelial cells. J Cell Physiol 2006, 208: I23-132.

27. Parthasarathi K, Ichimura H, Monma E, Lindert J, Quadri S, Issekutz A, Bhattacharya J: Connexin $\mathbf{4 3}$ mediates spread of Ca2+dependent proinflammatory responses in lung capillaries. $J$ Clin Invest 2006, I 16:2193-2200.

28. Pepper MS, Montesano R, el Aoumari A, Gros D, Orci L, Meda P: Coupling and connexin $\mathbf{4 3}$ expression in microvascular and large vessel endothelial cells. Am J Physiol 1992, 262: $\mathrm{Cl} 246-\mathrm{Cl} 257$

29. Hirschi KK, Burt JM, Hirschi KD, Dai C: Gap junction communication mediates transforming growth factor-beta activation and endothelial-induced mural cell differentiation. Circ Res 2003, 93:429-437.

30. Carmeliet P: Angiogenesis in health and disease. Nat Med 2003 , 9:653-660.

3I. Avanzo JL, Mesnil M, Hernandez-Blazquez FJ, da Silva TC, Fukumasu $\mathrm{H}$, Mori CM, Yamasaki H, Dagli ML: Altered expression of connexins in urethane-induced mouse lung adenomas. Life Sci 2006, 79:2202-2208. 
32. Sheen IS, Jeng KS, Wang PC, Shih SC, Chang WH, Wang HY, Chen CC, Shyung LR: Are gap junction gene connexins 26, 32 and 43 of prognostic values in hepatocellular carcinoma? A prospective study. World J Gastroenterol 2004, 10:2785-2790.

33. Stout $\mathrm{C}$, Goodenough DA, Paul DL: Connexins: functions without junctions. Curr Opin Cell Biol 2004, 16:507-5।2.

34. Evans $W H$, De Vuyst $E$, Leybaert $L$ : The gap junction cellular internet: connexin hemichannels enter the signalling limelight. Biochem / 2006, 397: I- I4.

35. el-Sabban ME, Pauli BU: Adhesion-mediated gap junctional communication between lung-metastatatic cancer cells and endothelium. Invasion Metastasis 1994, 14:164-176.

36. Wolosin JM, Schutte M, Chen S: Connexin distribution in the rabbit and rat ciliary body. A case for heterotypic epithelial gap junctions. Invest Ophthalmol Vis Sci 1997, 38:34I-348.

37. Dobrowolski R, Sasse P, Schrickel JW, Watkins M, Kim JS, Rackauskas M, Troatz C, Ghanem A, Tiemann K, Degen J, Bukauskas FF, Civitell $\mathrm{R}$, Lewalter T, Fleischmann BK, Willecke K: The conditional connexin 43G I 38R mouse mutant represents a new model of hereditary oculodentodigital dysplasia in humans. Hum Mol Genet 2008, I7:539-554.

38. Bellafiore M, Sivverini G, Palumbo D, Macaluso F, Bianco A, Palma A, Farina F: Increased cx43 and angiogenesis in exercised mouse hearts. Int J Sports Med 2007, 28:749-755.

39. Chen JT, Cheng YW, Chou MC, Sen-Lin T, Lai WW, Ho WL, Lee H: The correlation between aberrant connexin 43 mRNA expression induced by promoter methylation and nodal micrometastasis in non-small cell lung cancer. Clin Cancer Res 2003, 9:4200-4204.

40. Loewenstein WR, Kanno Y: Intercellular communication and the control of tissue growth: lack of communication between cancer cells. Nature 1966, 209:। $248-1249$.

41. Mesnil M, Crespin S, Avanzo JL, Zaidan-Dagli ML: Defective gap junctional intercellular communication in the carcinogenic process. Biochim Biophys Acta 2005, I 7 19: I 25- 145.

42. Wang H, Fu W, Im JH, Zhou Z, Santoro SA, lyer V, DiPersio CM, Yu QC, Quaranta V, Al-Mehdi A, Muchel RJ: Tumor cell alpha3beta I integrin and vascular laminin-5 mediate pulmonary arrest and metastasis. J Cell Biol 2004, 164:935-94I.

\section{Pre-publication history}

The pre-publication history for this paper can be accessed here:

http://www.biomedcentral.com/1741-7015/6/20/prepub
Publish with Bio Med Central and every scientist can read your work free of charge

"BioMed Central will be the most significant development for disseminating the results of biomedical research in our lifetime. "

Sir Paul Nurse, Cancer Research UK

Your research papers will be:

- available free of charge to the entire biomedical community

- peer reviewed and published immediately upon acceptance

- cited in PubMed and archived on PubMed Central

- yours - you keep the copyright
BioMedcentral 